\title{
Os efectos das infraestruturas humanas sobre a fauna galega de interese veterinario
}

Recibido: 27 xullo 2010 / Aceptado: 22 setembro 2010

(C) IBADER- Universidade de Santiago de Compostela 2010

\begin{abstract}
Resumo Nesta revisión exponse, de xeito resumido cales son os efectos das infraestruturas desenvolvidas polo home en Galiza (terra, mar e aire) sobre o benestar animal de diversas especies de interese veterinario. Estre traballo explora ademáis a eficacia de certas medidas para controlar os efectos negativos e as repercusións no medio ambiente de ditas infraestruturas.
\end{abstract}

Palabras chave Infraestruturas · Benestar animal · Galiza

Summary This review explains, in a summarised way the effects of human infrastructures in Galicia (land, marine and air) on animal welfare of such species with veterinarian interest. A critical analysis is presented about the convenience of certain tools (or means) to control the negative impacts of the mentioned infrastructures including their impacts on the environment

Keywords Infraestructures · Animal welfare · Galicia

\section{Introdución}

As infraestruturas humanas teñen efectos sobre a fauna do noso planeta: as cidades son un entorno artificial no que apenas queda vida salvaxe, pero a pesar disto, algunhas especies son capaces de desenvolverse sufrindo diferentes

Adrian Novo Piñeirúa · Rebeca Moralejo Silva · Ana Pascual Soares

Alumnos da Facultade de Veterinaria de Lugo $\left(2^{\circ}\right.$ ciclo $)$

Universidade de Santiago de Compostela

E-mail: cristina.castillo@usc.es

Este traballo realizouse baixo a supervisión e tutorización de Cristina Castillo, Profesora da Facultade de Veterinaria de Lugo (Departamento de Patoloxía Animal, Campus Universitario $\mathrm{s} / \mathrm{n}$, 27002 Lugo) e membro da Real Academia de Ciencias Veterinarias de Galicia (RACVG). adaptacións; o medio rural representaba o equilibrio entre o home e a natureza, pero na actualidade éste desplazouse cara á maior producción e comodidade do ser humano complicando a continuidade de determinadas especies. Elementos tan comúns e necesarios como un farol nunha rúa poden ter repercusións sobre a fauna. No caso do mundo mariño, os seres humanos están a alterar as costas cunha serie de infraestruturas que satisfacen as nosas necesidades (industrias, depuradoras, portos deportivos, recheos...). Todas elas, modifican o hábitat dos animais, de tal maneira que están a desaparecer varias especies autóctonas (ata 14 grupos de vertebrados segundo recolle o primeiro Catálogo Galego de Especies Ameazadas da Consellería de Medio Ambiente e Desenvolvemento Sostible da Xunta de Galicia e aprobado no ano 2007); moitas veces por non ter en conta o valor natural da zona. Feitos positivos para o medio como poden ser a reforestación ou a instalación de parques eólicos como enerxía renovable, son realmente negativos para certas especies animais, dificultándolles a adaptación a habitats cambiantes.

No seguinte traballo, tratamos de expoñer algúns dos efectos que provocan as instalacións humanas na fauna da terra, do mar e do aire.

\section{Infraestruturas terrestres}

Os efectos das mesmas teñen lugar tanto a nivel urbano como rural.

\section{Medio Urbano}

O desenvolvemento de este medio supón a creación dun asentamento artificial cómodo para o progreso social e comercial dos humanos. Esta concentración aumenta a demanda de recursos e favorece que o medio non poda asimilar o noso consumo, producíndose contaminación que afecta os animais que viven neste entorno e na periferia de varios xeitos: 


\section{Perda ou alteración do hábitat con superpoboación}

Varias son as razóns que levan á superpoblación de certas especies de aves: a atracción dos residuos humanos como fonte rápida e facil de alimento (nos vertedoiros), o abrigo, anidamiento e protección contra o frío ou as correntes de aire. Isto termina tendo efectos negativos, non só para o home (transmisión de enfermidades, acumulación de excrementos) senón tamén para o equilibrio poboacional doutras especies.

Como exemplo, sirva a superpoboación de gaivotas; aparte de favorecer a transmisión de enfermidades, ten efectos negativos sobre outras especies de aves mariñas; a de pombas xera situacións de competencia; no caso dos estorniños, éstes precisan lugares tranquilos para a cría e nas cidades prodúcese un nivel de estrés incompatible con ela.

Cidades coma A Coruña, Vigo e Ferrol contan con plans de xestión (a través da Consellería de Medio Rural da Xunta de Galicia), cuxo obxectivo e reducir o número de gaivotas ou estorniños. Algúns métodos consisten en esterilizar os ovos (sen retiralos); sacrifícar individuos con inxeccións intraperitoneais de pentobarbital; diminuír o acceso aos vertedoiros diminuíndo así a supervivencia dos polos nos primeiros anos; empregar dispositivos para evitar que se pousen (arames, púas ou pinchos) producindo dor e frustración ó non poder descansar; repelentes químicos e electrónicos que reproducen gritos agónicos e de ataque de aves para espantalas, ou mesmo luces en movemento que os asustan e desorientan, facéndoos fuxir sen rumbo.

Pero tamén hai outras especies que se atopan con problemas: as ratas, os morcegos, os lobos, os raposos, os xabarís... Estes últimos, fuxindo da caza, ou pola perda e fragmentación dos seus hábitats chegan as cidades onde debido a presenza humana, o tráfico ou a contaminación acústica, elevan o seu nivel de estrés e agresividade.

\section{Contaminación lumínica}

Os seres vivos adaptaron os seus procesos biolóxicos dacordo coa sucesión das estacións e a alternancia díanoite. A contaminación lumínica asociada aos núcleos urbanos ocasiona a necesidade de que as especies se adapten a estes cambios para non perecer. A orixe desta atópase en alumeados (ornamental, de seguridade, publicitarios, estradas, rúas peonís...). En xeral, a falta de escuridade altera o ritmo circadiano, os ciclos sono-vixilia, o mantemento da temperatura corporal, o estado de alerta, a visión nocturna, o cansazo, o nerviosismo...(Dolsa \& Albarrán, 2003).

Nas aves, a excesiva iluminación fai que píen durante a noite impedindo o descanso, alertando da súa presenza ós depredadores, diminuíndo a súa alimentación, e afectando os seus ciclos reprodutivos. O deslumbramento aumenta as colisións con edificios, causando a morte directa ou lesións que favorecen á depredación. A luminosidade provoca a concentración de insectos, favorecendo que as aves insectívoras adapten a súa alimentación, aínda que tamén, fainas mais visibles para os depredadores. Por outra parte, as aves migratorias nocturnas empregan o luar e as estrelas para a súa orientación, pero a continua iluminación provoca que as aves voen en círculos desorientadas ata quedar exhaustas ou que colisionen contra estruturas.

Nos mamíferos nocturnos o exceso de iluminación provócalles desnutrición progresiva, debido a que só utilizan os períodos escuros para alimentarse. A concentración de morcegos en torno aos farois en busca de comida, provoca gran transmisión de enfermidades entre depredadores e o esgotamento do alimento.

\section{Contaminación acústica}

Segundo a Organización Mundial da Saúde (OMS) o límite de decibelios considerado como adecuado na especie humana é de $50 \mathrm{~dB}$ (nunha conversa normal), en horarios diúrnos, e $30 \mathrm{~dB}$ pola noite. Unha rúa con moito tráfico alcanzaría os $70 \mathrm{~dB}$ e no interior dunha discoteca ata os 110 dB. A maioría das especies domésticas presentan unha maior sensibilidade que os humanos as frecuencias altas. Os centros emisores de ruídos abundan nas cidades e son o tráfico, as actividades industriais, as obras públicas e da construción, os servizos de limpeza e recollida de lixo, as sereas e as alarmas.

O ruído produce alteracións na conducta momentáneas, as cales consisten en agresividade, desinterese ou irritabilidade. Estas alteracións, que xeralmente son pasaxeiras provocan inquietude, inseguridade ou medo nalgúns casos. A longo prazo producen efectos negativos como a xordeira e a nivel psicolóxico, neurose, depresións, ansiedade, hostilidade, etc (Tolosa, 2003).

Investigacións como as de Hans Slabbekoorn e Ardie den Boer-Visser, da Universidad de Leiden (Holanda) no ano 2006 sobre os cantos dos pardais nas cidades, determinaron que os cantos vitais, como son os destinados á atracción de compañeiros e a defender o territorio, eran de maior frecuencia e mais curtos e rápidos que nos lugares forestais.

\section{Temperatura e humidade}

No medio urbano, o equilibrio natural da calor vese afectado, producindose o efecto illa de calor elevando as temperaturas na cidade entre $5^{\circ}$ e $10^{\circ} \mathrm{C}$. Este aumento, atrae a certas especies como estorniños, mouchos, pegas, ratas e cascudas provocando pragas e desprazando a outros animais.

O arrequecemento global, produce numerosos efectos sobre as especies. Se continúa, moitas aves desaparecerán en Galiza buscando veráns calorosos, invernos fríos e dispoñibilidade de auga no norte de Europa, predicen os autores do Atlas Climático de las Aves Reproductoras de Europa e publicado pola Sociedad Española de Ornitología (SEO/Birdlife)

\section{Contaminación química}

Segundo unha noticia aparecida no diario Faro de Vigo no ano 2008, Greenpeace considera que a planta incineradora de Sogama, as centrais térmicas de As Pontes, Meirama e Sabón, os materiais contaminantes dos edificios, e diferentes infraestruturas así coma a presenza de velenos 
raticidas nas rúas son só algúns dos exemplos dos contaminantes químicos ós que esta exposta a fauna galega.

Diversas organizacións ecoloxistas coma é Verdegaia veñen denunciando que a planta incineradora de Sogama, xera cinzas e escouras tóxicas e emite dioxinas e furanos, unhas substancias persistentes e bio-acumulativas. Comprobouse que doses non letais destes residuos nos animais poden producir cancro, defectos de nacemento, redución da fertilidade e cambios no sistema inmune.

O informe Impacto sobre a saúde das emisións dos grandes focos de contaminación realizado pola consultora inglesa EMRC (e publicado pola axencia EFE no ano 2006) xa sinalaba a central términa de As Pontes (A Coruña) coma o maior foco emisor de Europa de dióxido de xofre e de óxido de nitróxeno, con efectos perxudiciais sobre o aparello respiratorio (bronquite e exacerbación dos procesos asmáticos). Pero ademais destos compostos, as partículas en suspensión liberadas ao aire tamén eran capacer de provocar enfermidades (cancro de pulmón, mortes prematuras, arteriosclerose...)

O uso de materiais contaminantes en edificios, como formaldehido, amianto, chumbo, CFCs, disolventes tóxicos ou PVC (policloruro de vinilo), ocasiona un deterioro da saúde dos animais. A construcción, rehabilitación e demolición de edificios libera enormes cantidades destes residuos. Algúns, como o formaldehido, ou o amianto son coñecidos canceríxenos, outros, como o chumbo producen anemia, letarxia e síndromes neurolóxicos.

Non esquezamos a existencia de cebos envelenados, empregados para o control de certas especies como ratas ou cascudas que poden intoxicar a outros individuos, como ourizos...

\section{Vías de Comunicación}

As vías de comunicación supoñen a deforestación de amplas zonas e, en moitos casos, o seu trazado atravesa antigas rutas empregadas polos animais para conectar diferentes territorios, provocando a fragmentación dos seus hábitats e facendo que os animais teñan que modificar a ruta, ou arriscarse aos perigos das vías de comunicación, con atropelos, especialmente en xabarís, corzos e cabalos salvaxes.

O aumento da iluminación nas estradas non é efectivo, xa que os animais de vida nocturna son deslumbrados, deixándoos cegos e desorientados e aínda que perciban a proximidade dun perigo son incapaces de reaccionar. Por outra banda, son moitas as especies que teñen fototropismo positivo, e polo tanto son atraidas cara estas zonas onde se emite luz (Dolsa \& Albarrán, 2010)

Os corredores de vida silvestre habilitados para evitar que os animais salvaxes crucen as vías poden verse comprometidos por unha soa luz, evitando que os animais se despracen a determinadas áreas cruciais para a súa supervivencia.
Nas autoestradas pódense chegar a alcanzar niveis sonoros de ata $62 \mathrm{~dB}$ cos efectos antes descritos que afectarían ó desprazamento de moitas especies animais das súas rutas, así como á creación de impedimentos nas súas costumes de reproducción e alimentación. Iso sen contar coa presenza de gases contaminantes tales como monóxido e dióxido de carbono, dióxido de xofre, óxidos de nitróxeno, aldehidos, metais pesados e compostos orgánicos volátiles, tóxicos para o sistema respiratorio

\section{Medio rural}

É difícil establecer unha separación clara entre medio urbano e rural. As concentracións de chalets, as actividades industriais, a minería e as instalacións de ocio poderían considerarse rurais, pero sobre todo a baixa densidade de poboación e a presenza de actividades agropecuarias son o máis característico da paisaxe rural .

A perda de hábitat no medio rural galego é debida en gran medida as actividades agropecuarias tradicionais. Os cultivos supoñen alimento para as especies salvaxes e os depredadores acoden as áreas rurais na procura de gando. Isto perxudica ós labregos que tratan de impedir a súa presenza con diferentes métodos: cercas, valados, espantallos, espellos, artefactos sonoros, caza, velenos, etc. Manter aleixados ós animais é imposible se a presión no seu hábitat é maior, xa que a deforestación e a plantación de monocultivos desprazan á fauna autóctona (Ferrás et al. 2007).

O lobo ó competir co home como predador foi duramente perseguido, pero na actualidade, debido ó abandono do mundo rural e a desaparición dos gandeiros que exercían unha forte presión sobre él, está a recuperar os seus antigos territorios. A pesar diso, é unha especie cinexética combatida tamén con velenos e trampas.

Tanto a produtividade como a supervivencia xuvenil de lebres e coellos, dependen da calidade do hábitat, resultando moito mellores os hábitats pouco diversificados e monótonos, a diferencia dos galegos.

O corzo pode habitar case todas as formacións boscosas ibéricas, pero as variacións de refuxio, comida ou competencia, modifican aspectos da súa ecoloxía, afectando á súa densidade poboacional.

Os xabaríns asentados preto de campos de cultivo e mesmo no seu interior obteñen alimento de orixe humana. O abandono do medio rural esta facendo que esta poboación aumente. A superpoboación, a competencia, a hibridación con porcos domésticos e a caza son algúns dos problemas ocasionados polo home.

A construción de urbanizacións e centros de ocio como campos de golf en medio rural, supón unha das perdas mais agresivas do hábitat natural debido as grandes extensións de terreo e recursos que se necesitan para estas infraestruturas. Proxectos mineiros como o da mina de andalucita a ceo aberto de Pontedeume ameaza o espazo natural das Fragas do Eume, poñendo en perigo a supervivencia de tódalas especies animais que alí habitan 
pola diminución do seu hábitat, o aumento da presenza humana, os niveis de ruído elevados e unha contaminación ambiental superior á actual.

Os efectos da contaminación lumínica son os mesmos que os citados no medio urbano, cá diferencia de que o número de animais no rural é maior e as áreas iluminadas están máis dispersas, polo que os efectos son menos intensos pero mais amplos e con maior número de vítimas (Dolsa \& Albarrán, 2003).

O emprego de maquinaria agrícola e vehículos, producen ruídos que afectan á fauna local. Se temos en conta as industrias, as urbanizacións e todas as infraestruturas que colonizan este medio, o problema cada vez é máis parecido o da cidade.

A produción de residuos polas vivendas soe ser menor, pero son moitos os espazos rurais onde se poden atopar puntos negros que favorecen o acúmulo de diferentes tipos de residuos. Estes poden ser altamente contaminantes e alterar gravemente a saúde dos animais.

\section{Infraestruturas mariñas}

Segundo denuncian diversas organizacións ecoloxistas como é ADEGA ou Galicia Ambiental, a día de hoxe as actividades humanas preséntanse como o maior problema para todo o litoral galego. Son numerosas as infraestruturas (urbanizacións, depuradoras, industrias, portos deportivos, recheos...) que provocan unha ameaza para a fauna que habita no medio mariño.

\section{Depuradoras e Industrias}

Liberan gran cantidade de vertidos químicos, augas residuais, residuos orgánicos e inorgánicos, metais pesados e provocan contaminación acústica no ecosistema mariño.

Segundo informes elaborados por ADEGA, Galiza conta cun sistema de xestión de vertidos e de depuración de augas moi deficiente, que está a provocar grandes impactos sobre as rías e os organismos que habitan nelas. Cabe destacar a depuradora do Lagares en Vigo: ésta verte ó río 900 litros de auga sen depurar. Tan só Vigo, conta con máis de 2000 actividades industriais na costas e co porto con máis tráfico marítimo de Galiza.

\section{Vertidos químicos}

Dacordo cun informe elaborado no ano 2002 por ADEGA, destacan os hidrocarburos poliarómaticos $(\mathrm{PAH})$ vertidos ó mar por industrias petroleiras e durante o transporte marítimo principalmente. Os PAH acumúlanse nos seres vivos ó longo da cadea trófica e provocan unha serie de cambios físico-químicos das augas que se traducen en axentes estresantes para a fauna (diminución da osixenación do medio; modificacións do $\mathrm{pH}$ e da temperatura; acumulación nos sedimentos mariños; cambio de cor, olor e sabor...).

Varias son as especies afectadas polos seus efectos: no caso dos crustáceos, a maior parte dos cirrípedos (percebes) morren por asfixia, e os que sobreviven con petróleo adherido, demostran gran dificultade na respiración ou nutrición. Os decápodos (centolas e cangrexos) adultos resisten bastante a este tipo de contaminación, sen embargo, as larvas teñen que migrar a outro lugar. No que respecta aos moluscos, a maior parte dos que viven cerca do litoral son máis resistentes que os que viven mar adentro. Os bivalvos tales como os mexillóns captan os hidrocarburos (saturados e aromáticos) e os acumulan cunha pequena desintegración metabólica. En canto aos peixes, o petróleo e os seus derivados son altamente tóxicos para os ovos, polo que os peixes nados deses ovos son anormais. Os adultos, adquiren olor a hidrocarburo que se transmite a través das branquias.

Os efectos a longo prazo sobre os peixes, outros animais mariños e mamíferos xeneran cambios no metabolismo dos lípidos, con acumulación de graxas no fígado e outros tecidos. Pero as especies afectadas non son só as mariñas senon tamén as aves: o empetrolamento modifica a súa flotabilidade e o illamento térmico da plumaxe, provocándolles a morte por hipotermia e imposibilidade de voar

\section{Metais pesados}

Son contaminantes xenobióticos que se acumulan na cadea trófica e nos sedimentos mariños. Os que máis afectan á fauna mariña son cinc $(\mathrm{Zn})$, arsenico (As), cadmio (Cd), cobre $(\mathrm{Cu})$, chumbo $(\mathrm{Pb})$, cromo $(\mathrm{Cr})$ e mercurio $(\mathrm{Hg})$, que teñen a propiedade de acumularse nos organismos $\mathrm{e}$ nalgúns casos de transferirse pola cadea trófica. A contaminación con este tipo de metais na costa galega está á orde do día segundo ADEGA, destacando A Coruña (con contaminación moi alta para o $\mathrm{Cu}$, moderada para o Zn e $\mathrm{Pb}$ ); Pontevedra (contaminación considerable para o $\mathrm{Cu}$ ); San Simón (contaminación moi alta para o Pb); Redondela (contaminación considerable para o $\mathrm{Cu}$ ) ou mesmo a praia de Samil, en Vigo (contaminación moi alta para o $\mathrm{Pb}, \mathrm{Zn}$ e $\mathrm{Cu}$; considerable para o $\mathrm{Cr}$ ).

Entre as especies maís afectadas están os moluscos (mexillóns), que presentan unha gran capacidade de bioacumulación de $\mathrm{Zn}, \mathrm{Cd}, \mathrm{Pb}$ y $\mathrm{Cu}$ especialmente. En canto aos mamíferos mariños, o golfiño común, marsopa e golfiño listado mostran un aumento na concentración de $\mathrm{Zn}$ según afirma A. López, da Coordinadora para Estudios de los Mamíferos Marinos (CEMMA, Pontevedra). En canto aos peixes, o metilmercurio únese moi fortemente os tecidos e tarda moito en desaparecer (biomagnificación), finalmente nas aves afectadas se observan problemas para o voo, comportamentos anormais o mesmo alteracións na reprodución (por exemplo, o $\mathrm{Hg}$ se transfire á placenta e pode causar lesións nerviosas).

\section{Ruido}

O ruido submariño producido por actividades humanas inclúe o tráfico marítimo e as extraccións de petróleo e gas (sons de altas e baixas frecuencias). Ademáis dos buques 
mercantes hai que resaltar a proliferación de embarcacións dedicadas ó turismo e outras como motos acuáticas ou embarcacións lixeiras, que causan graves molestias nestos animais. $\mathrm{Na}$ actualidade existe únicamente nas illas Canarias unha lexislación que evita o achegamento inadecuado destas embarcacións aos cetáceos (López et al. 2003).

Dentro do conxunto dos factores de risco que pesan sobre o hábitat mariño, esta contaminación constitúe unha das maiores ameazas a curto plazo, e a escala mundial, para o equilibrio dos océanos.

Dado que os cetáceos dependen do son en todos os aspectos das súas vidas, non cabe dúbida de que son especialmente vulnerables ás fontes de ruido artificial (López et al. 2003). Os mecanismos de resposta deles a este tipo de contaminación son numerosos destacando cambios de comportamento, lesións graves e alteracións reprodutivas.

Pero a contaminación acústica tamén afecta ó resto da fauna mariña: no caso dos peixes (arenques) causa alteracións do crecemento, da acumulación de graxa e reducción dos índices reprodutivos. A exposicións de sons entre 40 e $50 \mathrm{~dB}$ provocan unha significativa diminución da viabilidade dos ovos e a redución da tasa de crecemento.

\section{Vertidos de materia orgánica}

Avalíase a través de diversos ensaios, sendo os máis comúns a determinación da Demanda Bioquímica de Osíxeno (DBO5 ou BOD5) e a Demanda Química de Osíxeno (DQO ou COD). Canto maior é a descarga de DBO5 e COD, en termos de $\mathrm{Kg} /$ día ou $\mathrm{Kg} / \mathrm{ano}$, maior é o risco para todos os habitantes vivos do río.

A metade destes vertidos nas rías galegas son xerados polas industrias, destacando as conserveiras e a industria de celulosa ENCE (Pontevedra) que chega ata os 8 millóns de $\mathrm{kg}$ de COD/ano, sindo considerada polos organismos ecoloxistas coma a responsable do maior vertido puntual de materia orgánica do litoral galego. Estes vertidos contribúen ao consumo de osíxeno da auga, xerando hipoxia e anoxia nos animais e á proliferación de microorganismos patóxenos.

As especies máis sensibles a esta contaminación son os peixes e os crustáceos; nestas ten lugar unha diminución nas súas tasas de crecemento e reprodución, estrés, migración forzada, redución do seu hábitat, aumento da vulnerabilidade á depredación, a interrupción dos seus ciclos vitais e finalmente a morte.

\section{Residuos inorgánicos}

Ás rías chegan cada día miles de residuos inorgánicos sobrantes da produción das industrias costeiras que posúen unha mala xestión dos mesmos. Coma consecuencia disto as especies mariñas vénse moi afectadas: confunden os residuos con alimento e sofren modificación do seu hábitat. Aves e mamíferos mariños así coma peixes son os máis afectados xa que a inxesta deste tipo de residuos provócalles normalmente a morte por asfixia.

\section{Peiraos, Recheos e Portos Deportivos}

Si botamos unha ollada á costa galega veremos unha morea de peiraos, recheos e portos deportivos que nos últimos anos están sendo ampliados e que son unha gran ameaza para os animais. Sinalamos como exemplos, o peirao da ría de Foz (Lugo) (que xera cambios na hidrodinámica da ría); o macrorecheo de Bouzas en Vigo (con contaminación lumínica e soterramento de bivalvos) e o porto deportivo de Vigo (con contaminación acústica, lumínica, vertidos de hidrocarburos e doutras sustancias químicas).

\section{Cambios na hidrodinámica das rías}

Segun estudos desenvolvidos por Castellanos et al. (2003), os cambios na hidrodinámica das rías levan consigo unha perda de productividade enorme, derivada da alteración na sedimentación das mesmas. Esto implica un cambio de hábitat para os seres acuáticos que se ven afectados. Un exemplo é a diminución de certas especies de bivalvos como o berberecho (Cerastoderma edule), consecuencia do incremento doutras especies (Zoostera spp.).

\section{Contaminación lumínica}

Os efectos sinalados para a contaminación lumínica das cidades (Dolsa \& Albarrán, 2003) poden ser aplicables a estas infraestruturas. Só sinalar que no caso das aves mariñas, cáusalles deslumbramento, desorientación durante as migracións (xa que algunhas guianse grazas as estrelas), alteracións na conducta de búsqueda de alimento, alteracións na reprodución e a morte por colisión ou quemaduras.

\section{Vertidos de substancias químicas}

Os portos son as principais áreas onde o tributilo de estaño (TBT) alcanza os seus niveis máis altos. Este composto estannico se emprega como principio activo nas pinturas antiincrustantes aplicadas ós barcos para retrasar o desenvolvemento de organismos adheridos a súa superficie. Os efectos que provocan nas especies acuáticas, considerado como un dos máis perigosos, son moitos: así, os moluscos bivalvos (ostras, ameixas...) posúen unha baixa actividade dos sistemas enzimáticos encargados de debutilar a substancia, sendo capaces de concentrar grandes cantidades (bioacumulación), sen embargo non existen estudos claros que aseguren a posibilidade de biomagnificación.

No caso dos moluscos gasterópodos prodúcese non só bioacumulación, senón que a concentracións moi baixas, en Nucella lapillus (unha especie de caracol mariño) provoca a aparición dunha anomalía chamada imposex e que é unha alteración do sistema endócrino: ten lugar nas femias e consiste no desenvolvemento de gónadas masculinas o que lles provoca esterilidade (Barreiro et ál. 2004). Finalmente, nas aves mariñas afectadas é frecuente o adelgazamento de cáscaras de ovos. 


\section{Infraestruturas aéreas}

Pese ós beneficios e comodidades que aportan algunhas estructuras creadas pola man do home, posúen numerosos efectos adversos en canto á fauna se refire.

\section{Instalacións Eléctricas de Alta Tensión}

Os accidentes en tendidos eléctricos, xa sexa por electrocución ou colisión aumentaron paralelamente ó desenvolvemento das liñas de tendido eléctrico, especialmente no medio rural (Carbonell, 2010). Prodúcese cando as aves en voo non son capaces de evitar os cables e chocan contra eles. A susceptibilidade varía entre especies dependiendo de características corporais (envergadura e peso); dos hábitos gregarios (medios abertos ou estepas) crepusculares ou nocturnos e da meteoroloxía. Unha gran porcentaxe das colisións prodúcense cando, en condicións de escasa visibilidade, remontan o voo para evitar os conductores e atopan o cable de terra, de grosor menor.

Atopamos dous factores que determinan o grao de risco: os técnicos (presenza de cable de terra, sección do conductor, disposición de fios en planos e amplitude dos vanos) e as áreas sensibles da trazada (zonas húmidas e cauces de río, esteparias, de paso migratorio e cortados rocosos).

Como posibles solucións, hai documentos como o publicado pola empresa IBERDROLA-REDEL no ano 2000, nos que contémplase evitar o trazado por áreas sensibles e situacións de risco; modificar o tipo de liña, como por exemplo no abastecemento de repetidores, (Tv, telefonía, pequenas instalacións agrícolas...); aínda que a opción máis óptima é emplazar unha caseta transformadora nun punto de menor altitude, e instalar un tendido en baixa tensión e cable seco trenzado ou soterrado, sinalado con balizas salvapaxaros e deseños de crucetas que disminúen o risco de electrocución para as aves.

\section{Reforestación}

A configuración física do territorio galego fai que os recursos (auga, terras de cultivo...) atópense espallados por toda a xeografía, o que condiciona unha elevada ocupación do espazo por parte do home, incompatible en ocasións co benestar de moitas especies.

Mentres a superficie arborada medra, as especies forestais pouco esixentes desaparecen; non é o mesmo ter un cultivo forestal de eucalipto ou piñeiro que un bosque. Pero aínda hai máis, a calidade ambiental dos bosques existentes diminúe progresivamente; cada día están máis fragmentados e illados e a súa diversidade estrutural é menor; as árbores máis grandes desaparecen, apenas hai troncos mortos no sotobosque fundamentais para o refuxio da fauna invertebrada da que se alimentan moitas especies (Teixido et ál. 2009).

De acordo ao Catálogo Nacional de Especies Amenazadas, publicado polo Ministerio de Medio Ambiente, Medio Rural y
Marino con data 12 de xullo de 2005, a poboación de pita do monte (Tetrao urogallus) restrínxese ós Ancares debido a deteriorización do límite entre bosque e matorral; a apertura de pistas forestais; as molestias por parte de cazadores e excursionistas e, posiblemente, ó cambio climático. Da mesma forma, especies como a arcea (Scolapax rusticola), o papamoscas cincento (Muscicapa striata) e o rabirudo de testa blanca (Phoenicusrus phoenicurus) poden desaparecer en pouco tempo, entre outras causas, por falta de bosques e de ocos nas árbores nos que aniñar. Algunhas, precisan dun bosque e áreas abertas para sobrevivir, como a águia calzada (Hieraetus pennatus). 0 pardal montés (Passer montanus) é difícil de atopar por causa da tala de árbores frutais, en cuxos ocos facían os niños. Finalmente, destacar a sensibilidade dos falcóns pelegríns (Falco peregrinus) a determinados pesticidas.

En xeral, as especies de aves con fortes requerimentos xeolóxicos están nunha situación moi desfavorable en Galiza. As únicas non ameazadas serían aquelas que non teñen esixencias específicas estritas, xeralistas capaces de sobreviviren ainda que estraguemos o entorno.

\section{Parques Eólicos (Terrestres e Mariños) e Aeroportos}

A enerxía eólica emprégase como ferramenta contra o cambio climático ó reducir a dependencia de combustibles fósiles e por tanto, diminuir as emisións nocivas de gases de efecto invernadoiro, sen embargo a súa producción non está exenta de consecuencias negativas, especialmente nas aves (Vispo, 1999).

A ausencia en España dunha Avaliación Ambiental Estratéxica de plans e programas de enerxía eólica propiciou que a rápida proliferación de parques eólicos producírase, en moitas ocasións, sen unha adecuada planificación e seguemento destos, xerándose así un incremento dos efectos negativos que provocan na fauna local

Según sinala Atienza et al. (2008), os principais impactos sobre eles pódense resumir en:

Impacto directo: Por colisións contra diversos elementos (rotores, aspas, torre, estruturas asociadas) dando lugar a lesións. A maiores, a súa presenza provócalles un desprazamento de hábitat que pode dar lugar a un desequilibrio da reprodución e, polo tanto, a unha perda de poboación. Cabe destacar o efecto barreira, xa que supón un impedimento para a mobilidade das aves (alimentación, invernada, cría e muda), ademáis, os rodeos que ten que facer provócanlles un maior gasto enerxético que pode chegar a mermar o seu estado físico.

Impactos indirectos: A construción e a explotación dun parque eólico conlevan a instalación doutros elementos auxiliares como accesos á Rede Eléctrica Nacional. Estos elementos, a súa vez, poden xerar unha serie de impactos negativos propios sobre o medio ambiente: alteración e destrución do hábitat, destrución de postas e camadas, molestias, electrocucións, electromagnetismo, erosión, alteración do fluxo hídrico, etc. 
Impactos inducidos: Debido ao aumento da presión humana sobre os ecosistemas naturais e que pode conlevar ao aumento da presión cinexética e recoletora, ou do risco de incendios non naturais. Tamén pode incluírse o efecto derivado da utilización dos viais de acceso por parte de motoristas, todoterreos ou paseantes.

Impactos acumulativos: Tamén pódense dar efectos acumulados con outras infraestruturas na zona (por exemplo, moitos paseriformes son susceptibles de colisionar coas aspas dos molinos, pero tamén contra os vehículos das estradas próximas).

Hoxe en día, en Galiza existe un Mapa Eólico Mariño aprobado no ano 2009 polos Ministerios de Medio Ambiente, Medio Rural y Marino, así como o de Industria, Turismo y Comercio, e que representa as zonas favorables, favorables condicionadas e desfavorables para levar a cabo a súa instalación no noso litoral. Todos os efectos da instalación dos aeroxeradores que imos relatar están baseados en parques eólicos de Dinamarca, por ser a rexión de Europa con máis parques mariños. Así, os estudos existentes ata a data demostran que os grupos faunísticos máis afectados no caso dos parques terrestres son as aves e os morcegos. No caso dos morcegos, vense máis afectados a comezo do verán e en outono, xa que son especies migradoras, aínda que as especies sedentarias tamén vénse alteradas.

No caso dos parques mariños son os cetáceos e as aves mariñas: aos cetáceos, provócalles desorientación debido ós campos electromagnéticos provocados polas conexións dos cables destas instalacións; cambios de conducta (migracións, búsqueda de alimento, apareamento...) e alteracións anatómicas (rotura de tímpano, vibracións de cavidades orgánicas...) causadas polo ruido xerado na construcción, mantemento e funcionamento deles. Para as aves mariñas, os efectos son os mesmos que no caso dos eólicos terrestres.

Actualmente, non existen en España directrices para a avaliación dos impactos ecolóxicos provocados pola implantación de parques, xa sexan terrestres, costeiros ou mariños. Segundo sinala a propia Consellería de Medio Rural da Xunta de Galicia, a Avaliación de Impacto Ambiental (AIA) é a ferramenta que debe proporcionar medios para integrar factores ambientais no planeamento e toma de decisións, de forma que se reduzan as consecuencias negativas para o medio.

\section{Conclusións}

Toda a sociedade entende que as enerxías renovables son a mellor opción para a ecoloxía do planeta, pero... ¿é isto verdade, ou é, como todo, subxectivo? A falta dunha lexislación maís precisa sobre este tipo de construcións provoca que en ocasións se constrúan instalacións en zonas non aptas para elas ou tamén que non se teña en conta os seus efectos a medio-longo prazo sobre a entorno animal.

Todos somos conscientes de que o progreso e o benestar ten un prezo, pero sempre considerando os riscos que entraña a creación de novas infraestruturas, co fin de minimizar ou polo menos controlar, devanditos riscos. Aquí, o termo sostible alcanza o seu máximo sentido. Facemos unha chamada de atención cara á observación e control de todas aquelas especies animais vinculadas estreitamente ao home a través de diversos aspectos, e que poden ver arriscada a súa supervivencia, ou o seu benestar.

\section{Bibliografía}

Ferrás, C., Macía, J.C., García, Y., Armas, F.J. (2007). La agricultura familiar sostenible en sistemas minifundistas. Estudio de casso comparados en Galicia e Irlanda. Ager: Revista de estudios sobre despoblación y desarrollo rural (6): 101-128.

Tolosa, F. (2003). Efectos del ruido sobre la salud. Discurso inaugural del Curso Académico 2003 en la Real Academia de Medicina de las Islas Baleares. Dispoñibel en: http://www.ruidos.org/Documentos/Efectos ruido salud.ht $\underline{\mathrm{ml}}$

Asociación para a defensa ecolóxica de Galiza (ADEGA). Dispoñibel en: http://adega.info

Barreiro, R., Quintela, M. \& Ruiz, J.M. (2004). TBT e imposex en Galicia: los efectos de un disruptor endocrino en poblaciones de gasterópodos marinos. Ecosistemas 13 (3): 13-29.

Carbonell, R. (2010). Los tendidos eléctricos y los peligros sobre las aves. Dispoñibel en:

http://www.ucm.es/info/biologia/actualiz/temp/tendidos.htm.

Castellanos, C., Hernández-Vega, S. \& Junio, J. (2003). Cambios bentónicos en la ría de Foz (Lugo) (noroeste de España) tras la construcción de un espigón. Boletín del Instituto Español de Oceanografía, Vol. 19 (1-4): 205-218.

Consellería de Medio Rura, Xunta de Galicia (2010).

Dispoñibel en:

http://mediorural.xunta.es/areas/infraestruturas/presentacio n/

Coordinadora para el Estudio de los Mamíferos Marinos-

Galicia (CEMMA). Dispoñibel en:

http://www.arrakis.es/ cemma

Dolsa, A.G. \& Albarrán, M.T. (2003). La problemática de la contaminación lumínica en la conservación de la biodiversidad. I Sesión de trabajo sobre la Contaminación Lumínica Departament de Medi Ambient Generalitat de Catalunya. Dispoñibel en:

http://www.um.es/eubacteria/Biodiversidad.pdf.

EFE (2008). Ence, Sogama y Elnosa, príncipales focos contaminantes de Galicia según Greenpeace El Faro de Vigo, 11 de febreiro de 2008.

Galicia Ambiental (2009). La contaminación acústica aumenta en Galicia Galicia ambiental (en liña) Dispoñibel en: http://www.galiciaambiental.net/

GREENPEACE. Dispoñibel en: http://www.greenpeace.org/espana/reports. 
IBERDROLA-REDEL. (2000). Anexo F (00-11) Protección de la avifauna. Manual técnico de distribución. Dispoñibel en:

http://www.coitiab.es/reglamentos/electricidad/reglamentos

Atienza, J.C., Martín, I., Infante, O. \& Valls, J. (2008). Directrices para la evaluación del impacto de los parques eólicos en aves y murciélagos (versión 1.0). SEO/BirdLife, Madrid.

López, A., Sagarminaga R. \& Losada S. (2003). Cetáceos en un Océano Degradado: el Caso Español. Dispoñibel en: http://www.greenpeace.org/raw/content/espana/reports
Slabbekoorn, H. \& den Boer-Visser, A. (2006). Cities change the songs of birds Current Biology, 16 (23): 2326-2331.

Sociedad Española de Ornitología (SEO/Birdlife). Dispoñibel en: http://www.seo.org.

Teixido, A.L., Quintanilla, L.G., Carreño, F. (2009). Fragmentación del bosque y pérdida del hábitat de helechos amenazados en el Parque Natural Fragas do Eume (NW de España). Ecosistemas 18 (1): 60-73.

Vispo, D. (1999). Eólica sí, maís non así. Revista Galega de Ecoloxía e Medio Ambiente (CERNA), 28. 